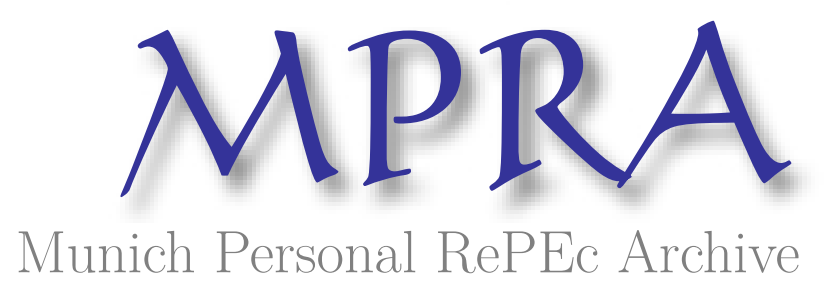

\title{
Does Financial Growth lead Economic Performance in India? \\ Causality-Cointegration using Unrestricted Vector Error Correction Models
}

Kamat, Manoj and Kamat, Manasvi

Indian Institute of Technology Bombay, Goa University

11 November 2007

Online at https://mpra.ub.uni-muenchen.de/6154/

MPRA Paper No. 6154, posted 07 Dec 2007 14:34 UTC 


\title{
Does Financial Growth lead Economic Performance in India? \\ Causality-Cointegration using Unrestricted Vector Error Correction Models
}

\author{
Mr. Manoj Subhash Kamat** \\ Mrs. Manasvi M. Kamat*
}

\begin{abstract}
Using contemporary models this paper explores the time-series properties of financial infrastructure and economic growth indicators to investigate the nexus between developments in financial intermediation with the economic growth for India over the 1971-2004 periods. Both over short-run and the long-run perspective the paper seeks to answer; whether the financial infrastructure variables are complementary or a substitute for economic performance? and in what way economic growth is affected by the financial infrastructural development indicators? We find evidence in favor of a short run "financial infrastructure led economic growth". Finance is found to be a leading sector only in the short-term link in Granger causality tests with stationary variables. The study provides robust empirical evidence in favor of supply leading hypothesis for the Indian economy.
\end{abstract}

Keywords: Finance, Infrastructure, Development, Economic Growth, Lag-lead, Granger Causality, Cointegration, VAR, VECM, India

Research Scholars, Indian Institute of Technology Bombay** and Goa University* (India)

Correspondence: (The first author) Mr. Manoj Subhash Kamat, mskamat@iitb.ac.in 


\title{
Does Financial Growth lead Economic Performance in India?
}

Causality-Cointegration using Unrestricted Vector Error Correction Models

\author{
Mr. Manoj Subhash Kamat and Mrs. Manasvi Manoj Kamat
}

\section{Introduction}

It is generally experienced that the advanced economies have well established financial systems ably backed by sophisticated financial infrastructure. Financial infrastructure or intermediation comprises of closely connected institutions, agents, regulations, transactions and market practices. Though close observations on the subject suggest that improvements in such financial arrangements strongly correlate with economic performance, mere existence of association may not necessarily imply causation. Though the quick survey of the recently available empirics on the subject reviewed herein, or the one by Niles (1994) published a decade earlier, remains inconclusive; Researchers like that of Levine and Zervos (1998), Khan and Senhadji (2000) show that a well-established financial market can not only can mobilize capital and diversify risks between market agents, can also be able to provide different types of services that can stimulate economic growth. Conceptually, welldeveloped financial infrastructure is important for growth due the efficient underlying functions the financial institutions are expected to perform. At one level financial intermediary help transfer of funds in exchange for goods, services, or promises of future return $\&$ enable the process of saving and capital accumulations. At a deeper level the financial infrastructure should be seen as one that perform several transformative services like that of accepting deposits as liability and converting them into assets such as loans (liability-asset transformation), by providing large volumes of finance on the basis of unit capital (size transformation), by reducing risk through aggregation and enabling it to be carried by those more willing to bear it (risk-transformation) and by providing borrowers with loans of requisite maturities (maturity transformation).

It thus follows from the above proposition that the evolution of financial infrastructure has a great impact on the economic activity for any given nation. If it is true, then domestic financial infrastructure development is also expected to have significant liaisons with the economic growth. Using time-series models this paper firstly explores the time-series properties of financial infrastructure development and 
economic growth and secondly through the Unrestricted Vector Error Correction framework discusses the nexus between developments of financial intermediation with the economic growth activity for India over different periods ranging 1971 through 2004. Both over short-run and the long-run perspective the paper seeks answer; whether the financial infrastructure variables are complementary or a substitute for financial and economic performance? In what way economic growth is affected by financial development? And finally to which extent has the thrust on financial infrastructure affected the growth in the economic activity. The principle question underhand is thus to re-examine the "financial infrastructure development and economic growth puzzle" from a developing economy perspective.

\section{Objectives \& Significance}

The objective of the present study is to contribute to the existing debate on financial development and the economic growth nexus, by analyzing the time-series for India over a longer time-frame of 34 years. The present study aims at threepronged objectives. This work is the foremost attempt to quantify the extent and the magnitude of select financial infrastructure development indicators on the economic performance. Secondly, we test the time-series properties of those variables to analyze the dynamic co-integrating behavior of the time-series in the short run and the long run. Finally, statistically detect the direction of causality (cause and effect relationship) in a multivariate setting when temporally there is a lead lag relationship between financial infrastructure development indicators with that of the economic activity.

Understanding the causal relationship between financial development and economic growth is important in enhancing the efficacy of policy decisions for a developing country like India. The importance of the debate for developing countries comes from the fact it has important policy implications for priorities that should be given to reforms of the financial sector by public authorities. The pinpoint focus on creation of an efficient infrastructure network can ignite development in other sectors, while its shortage or over-expansion can raise costs and create disincentives. Moreover, the causality issue between financial activity and economic growth in such countries is still very far from being settled. Our study is different from the rest in many ways. Earlier studies are based on cross-country analysis, moreover relate to developed countries alone. Related researches done in the past three decades mostly 
focused on the role of financial development in stimulating economic growth, without taking into account of the stock market development. Apart from infrastructure-growth debate we proceed to deliberate on the specific effect of postliberalization financial intermediary development on the financial sectors aiming at developing contribution in the economic growth process. Thus, the investigated issue will be useful either for researchers and policy makers looking for optimal policies to institute competitive economic growth.

\section{Organization}

In the remainder of the paper, we review the available literature in section 2. Sections $3 \& 4$ describe the data and lay the econometric methodology respectively. Section 5 presents and analysis through the results obtained from the different tests, while the final section (6) concludes.

\section{Underlying Theories and Empirical Evidence}

Theoretically, in the environment friendly, appropriate technology based, decentralized Alternative Development Model, finance is not a factor of crucial in economic development. In the convential model of modern industrialism however the perceptions in this regard vary a great deal, Bhole (1999). The theoretical literature and cross-sectional results on the topic can be loosely grouped into three main categories; Supply Leading approach, a Demand Following approach and a Cautionary or Feedback approach. According to the first, financial activity is considered as a major determinant of real activity where well functioning financial systems are crucial for economic growth. The "finance-led growth" hypothesis postulates the "supply-leading" relationship between financial and economic development. It is argued that the existence of the financial sector as well-functioning financial intermediations in channeling the limited resources from surplus units to deficit units, would provide efficient allocation resources thereby leading the other economic sectors in their growth process. Indeed, a number of studies (from Schumpeter, 1912 to Levine, 1997) have argued that the development of financial sector has significantly promoted economic development. For the second approach, financial activity is taken to be a result of economic growth where growing activities require more and more funds for expansion. The "growth-led finance" hypothesis states that a high economic growth may create demand for certain financial 
instruments and arrangements and the financial markets are effectively response to these demands and changes. In other words, this hypothesis suggests a "demand following" relationship between finance and economic developments. Such impact of economic growth on the financial development has been documented in Robinson (1952) and Romer (1990) among others. The third, "feedback" hypothesis suggests a two-way causal relationship between financial development and economic performance. In this hypothesis, it is asserted that a country with a well-developed financial system could promote high economic expansion through technological changes, product and services innovation. This in turn, will create high demand on the financial arrangements and services. As the banking institutions effectively response to these demands, then these changes will stimulate a higher economic performance. Therefore, both financial development and economic growth are positively interdependent and their relationship could lead to feedback causality. The work of Luintel and Khan (1999), among others, is supportive of this view.

Though the relationship between financial development and economic growth has been extensively studied in the recent decades, the issue is not new in development economics and may go back at least to Schumpeter (1912) who stresses the importance of financial services in promoting economic growth. The attempt of Patrick (1966) is among the foremost in discussing the association between economic growth and financial development in under-developed countries. Cameron (1967) has shown that in the present developed countries, the developed financial systems generally evolved during the early stages of industrialization. The literature by Greenwood and Jovanovic (1990), Bencivenga and Smith (1991), Roubini and SalaI-Martin (1992), Pagano (1993), King and Levine (1993b), Berthelemy and Varoudakis (1996), Greenwood and Smith (1997) support the view that financial development (repression) has positive (negative) effects on economic growth in the steady state. Of the above, the studies by Roubini and Sala-I-Martin (1992), King and Levine (1993), Fry (1997), Levine and Zervos (1998) widely use cross-sectional techniques to support the hypothesis that financial sector development is growth enhancing and consequently financial repression policies are harmful for economic growth. Robinson (1962) for example, has suggested, in an original position, that financial development follows economic growth. Newlyn (1977) considers the role of finance in development as of subsidiary in nature. Likewise, Lucas (1988) concludes that the importance of financial markets is badly overstressed. A similar 
conclusion is shared by Chandavarkar (1992) who considers that finance is never been listed by the pioneers of development economics as a key development factor. Building on the work of Schumpeter (1912), Gurley and Shaw (1955), Goldsmith (1969), McKinnon (1973) and Shaw (1973) propounded the financial "liberalization paradigm", according to which the public regulation of the banking system reduces the quality and quantity of capital accumulation. The World Bank (1989) defends this liberal views and state, that an efficient financial system help to grow, partly by mobilizing additional financial resources and partly by attracting those resources to the best uses.

Earlier Causality pattern based studies include that of Sims (1972), Gupta (1984), Jung (1986), Toda and Phillips (1993), Murende and Eng (1994), Demetriades and Hussein (1996), Arestis and Demetriades (1996) and Kul and Khan (1999) find that the causality pattern varies across countries and with the success of financial liberalization policies implemented in each country and with the development level of the financial sector generally.

\section{Data Sources and Variables}

The necessary secondary data for India (in Indian Rupees) for the period 1971-2004 is adjusted for inflation using the Wholesale Price Index (WPI) and emerge from number of sources namely, the Handbook of Statistics on the Indian Economy, published and the annual reports published by the Reserve Bank of India, the Handbook of Statistics on the Indian Securities Markets as well as the annual reports of the Securities Exchange Board of India, the website of the Bombay Stock Exchange, and the other regular publications on capital markets by the Centre for Monitoring of the Indian Economy (CMIE).

To measure the dependent variable economic growth (EG), we use the growth rate in Gross Domestic Product (GDP) at factor cost \& current prices, based on new series with 1993-94 as the base year. This is in line with the standard literature on the ties between economic growth and financial activity and specifically in the recent work on the subject by Demetriades and Hussein (1996), Luintel and Khan (1999) and others. The other indicator of financial development used in the model is Financial Activity (FA) emerging from productive investments by the private corporate sector and is defined as the ratio of Gross Capital Formation (GCF) by the Private Sector to GDP. The stage of market development, of the macro 
economy, the interaction of institutions, markets and market practices, all have a positive influence on the real decisions on the firm and therefore, on the overall capital formation in the corporate sector. The second variable, (FS) is the ratio of Financial Savings to GDP. Financial savings is measured by the difference between M3 and M1. The subtraction of the money stock (M1) aims at getting the quasi-liquid assets considered as the main source of investment financing. A rising ratio of financial savings to GDP may reflect an improvement in bank deposits and / or other financial resources outside the banking sector, which are likely to be used for accumulation and growth. Financial Deepening (FD) indicator is the ratio of the total assets of the financial system to nominal GDP and is calculated as the ratio of the liquid liabilities (M3) to the nominal GDP. M3 is a broader measure of money stock in accordance with the inside money model of McKinnon (1973) where the accumulation of real money balances is a required condition for investment. An increase in this ratio may be interpreted as an improvement in financial deepening in the economy. In order to avoid the simultaneity bias in our equations, the Liquidity Adjustment (LA) measure is included as the control variable. We choose Bank Rate as monetary authority's tool in adjusting the market liquidity and economic performance, as the intervention of government or monetary authority could affect the relationship between financial and economic development. Government through the central bank can adjust the liquidity level in the equity market and then influence the ability of banking institutions in supplying their funds. The bank rate in India apart from the basic rate of refinance and rediscounting facilities is also the reference rate to which all interest rates on advances from the bank, the penal rates on the shortfall in the reserve requirements, and the maximum term deposit rates of the banks are linked. An increase in the bank rate will reduce any lead to lower investments, the level of market liquidity and then slow down the economic activity.

\section{Research Techniques}

\section{Unit Root testing}

In the first stage, the order of integration is tested using the Augmented Dicky Fuller (ADF) and the Philip-Perron (PP) unit root tests. Unit Root tests are conducted to verify the stationarity properties (absence of trend and long-run mean reversion) of the time series data so as to avoid spurious regressions. A series is said to be (weakly or covariance) stationary if the mean and autocovariances of the series do not depend 
on time. Any series that is not stationary is said to be non-stationary. A series is said to be integrated of order $\mathrm{d}$, denoted by $\mathrm{I}(\mathrm{d})$, if it has to be differenced $\mathrm{d}$ times before it becomes stationary. If a series, by itself, is stationary in levels without having to be first differenced, then it is said to be $\mathrm{I}(0)$. Consider the equation

$y_{t}=\rho y_{t-1}+x_{t}^{\prime} \delta+\varepsilon_{t}$

Where $x_{t}$ are optional exogenous regressors which may consist of constant, or a constant and trend, $\rho$ and $\delta$ are parameters to be estimated, and $\varepsilon_{t}$ is assumed to be white noise. If $|\rho| \geq 1, \mathrm{y}$ is a nonstationary series and the variance of $\mathrm{y}$ increases with time and approaches infinity if $|\rho|<1$, y is a (trend) stationary series. Thus, the hypothesis of (trend) stationarity can be evaluated by testing whether the absolute value of $\rho$ is strictly less than one.

We use ADF test using MacKinnon (MacKinnon, 1991) critical values. This test constructs a parametric correction for higher-order correlation by assuming that the $y$ series follows an $\mathrm{AR}(\mathrm{p})$ process and adding $\mathrm{p}$ lagged difference terms of the dependent variable y to the right-hand side of the test regression

$$
\Delta y_{t}=\alpha y_{t-1}+x_{t}^{\prime} \delta+\beta_{1} \Delta y_{t-1}+\beta_{2} \Delta y_{t-2}+\ldots+\beta_{p} \Delta y_{t-p}+v_{t}
$$

This augmented specification is then used to test the hypothesis

$H_{0}: \alpha=0$, against $H_{1}: \alpha<0$

If we could not reject the null hypothesis $\mathrm{H}_{0}: \alpha=0$, it meant that $\alpha=0$ and the series $\alpha$ contains a unit root. Where $\alpha=\rho-1$ and evaluated using the conventional t-ratio for $\alpha$

$t_{\alpha}=\hat{\alpha} /(\operatorname{se}(\hat{\alpha}))$

Where $\hat{\alpha}$ is the estimate of $\alpha$ and $\operatorname{se}(\hat{\alpha})$ is the coefficient standard error

An important result obtained by Fuller is that the asymptotic distribution of the t-ratio for $\alpha$ is independent of the number of lagged first differences included in the ADF regression. ADF tests are tried with constant and trend terms, and with constant only. Inclusion of a constant and a linear trend is more appropriate, since the other two cases are just special cases of this more general specification. However, including irrelevant regressors in the regression will reduce the power of the test to 
reject the null of a unit root. For considering appropriate lag lengths, we use the VAR process in conjunction with the Lag range selection test.

Phillips (1987) and Phillips-Perron (1988) suggest an alternative approach for checking the presence of unit roots in the data. They formulate a nonparametric test to the conventional t-test which is robust to a wide variety of serial correlation and time dependent hetroscedasticity. The PP unit root test requires estimation of the following equation (without trend).

$$
X_{t}=\mu_{t}+\sum_{i=1}^{\mathrm{T}} X_{i-T}+u_{t}
$$

The bias in the error term results when the variance of the true population differs from the variance of the residuals in the regression equation. PP test statistic reduces to the DF test-statistic when auto correlation is not present.

$$
\sigma_{u}^{2}=\lim _{\mathrm{T} \rightarrow \infty} \mathrm{T}^{-1} \sum_{t=1}^{\mathrm{T}} \mathrm{E}\left(\mathrm{u}_{1}^{2}\right)
$$

Consistent estimators of $\sigma^{2}$ and $\sigma_{u}^{2}$ are

$$
\begin{aligned}
& \mathrm{S}_{\mathrm{u}}^{2}=\mathrm{T}^{-1} \sum_{\mathrm{t}=1}^{\mathrm{T}}\left(\mathrm{u}_{\mathrm{t}}^{2}\right) \\
& \mathrm{S}_{\mathrm{Tk}}^{2}=\mathrm{T}^{-1} \sum_{\mathrm{t}=1}^{\mathrm{T}}\left(\mathrm{u}_{\mathrm{t}}^{2}\right)+2 \mathrm{~T}^{-1} \sum_{t=1}^{k} \sum_{t=j+1}^{\mathrm{T}} u_{t} u_{t-j}
\end{aligned}
$$

Where $\mathrm{k}$ is the lag truncation parameter used to ensure that the auto-correlation is fully captured.

The PP test-statistic under the null-hypothesis is of I(0)

$$
Z\left(t_{\mu}\right)=\left\langle S_{u} \mid S_{t k}\right\rangle t_{\mu}-1 / 2\left(S_{t k}^{2}-S_{u}^{2}\right)\left[S_{t k}\left\{T^{2} \sum_{t=2}^{T}\left(Y_{t}-Y_{t-1}\right)^{2}\right\}^{1 / 2}\right]
$$

\section{Multivariate Cointegration}

The Cointegration tests are applied to detect the presence of any long-term relationship between the variables. Engle and Granger (1987) points that a linear combination of two or more non-stationary series may be stationary and if such a stationary linear combination exists the non-stationary time series are said to be cointegrated. The stationary linear combination is called the cointegrating equation and may be interpreted as a long-run equilibrium relationship among the variables. The purpose of the cointegration test is to determine whether a group of nonstationary series is cointegrated or not. For two series to be cointegrated, both need to 
be integrated of the same order, 1 or above. If both series are stationary or integrated of order zero, there is no need to proceed with cointegration tests since standard time series analysis would then be applicable. If both series are integrated of different orders, it is safely possible to conclude non-cointegration. Lack of cointegration implies no long-run equilibrium among the variables such that they can wander from each other randomly. Their relationship is thus spurious. For any $k$ endogenous variables, each of which has one root, there will be 0 to $k-1$ cointegrating relationships. The Residual-based approach proposed by Engle and Granger (1987) and the maximum likelihood method developed by Johansen and Juselius (1990). This test helps ascertain the existence of a long-run equilibrium relationship between economic growth and select financial development indicators in multivariate setting.

As suggested above, a set of variables is said to be cointegrated if a linear combination of their individual integrated series $1(\mathrm{~d})$ is stationary. All the time series, are individually subjected to unit root analysis to determine their integrating order and if they are stationary of a given order, in order to estimate the cointegration regression equation, we regress $\mathrm{EG}$ on other financial indicators as follows

$$
E G_{t}=\beta_{1}+\beta_{2} G F A_{t}+\beta_{3} G F S_{t}+\beta_{4} G F D_{t}+\beta_{5} G L A_{t}+u_{t}
$$

This can respectively, be written as

$$
u_{t}=\left(E G_{t}-\beta_{1}-\beta_{2} F A_{t}-\beta_{3} F S_{t}-\beta_{4} F D_{t}-\beta_{5} L A_{t}\right)
$$

If the residuals, $u_{t}$ from the above regressions are subject to unit root analysis are found $1(0)$ i.e. stationary, then the variables are said to be cointegrated and hence interrelated with each other in the long run or equilibrium. If there exists a long term relationship between the above two series, in the short run there may be a disequilibrium. Therefore one can treat the error term $u_{t}$ in the above equations as the "equilibrium error". This error term can be used to tie the short run behavior of the dependent variable to its long-run value.

The error correction mechanism (ECM) corrects for disequilibrium and the relationship between the two cointegrating variables can be expressed as ECM as under.

$$
\Delta E G_{t}=\alpha_{0}+\alpha_{1} \Delta F A_{t}+\alpha_{2} \Delta F S_{t}+\alpha_{3} \Delta F D_{t}+\alpha_{4} \Delta L A_{t}+\alpha_{5} u_{t-1}+\varepsilon_{t}
$$


Where, $\Delta$ denotes the first difference operator, $\varepsilon_{t}$ is the random error term and $u_{t-1}$ in equation 11 is the lagged term consisting of

$u_{t-1}=\left(E G_{t}-\beta_{1}-\beta_{2} F A_{t}-\beta_{3} F S_{t}-\beta_{4} F D_{t}-\beta_{5} L A_{t}\right)$ and

ECM equation 12 states that the dependent variable depends not only on the specified independent variables but also on the equilibrium term. If the later is non zero, the model is out of equilibrium. If the concerned independent variable is zero and $u_{t-1}$ is positive, the dependent variables are too high to be in equilibrium. That is, the respective dependent variable is above its equilibrium value of $\left(\alpha+\alpha_{1}\right.$ independent variables $\left._{t-1}\right)$. Since $\alpha_{2}$ is expected to be negative, the term $\alpha_{2} u_{t-1}$ is negative and, therefore, dependent variable will be negative to restore the equilibrium. That is, if the dependent is above its equilibrium value, it will start falling in the next period to correct the equilibrium error. By the same token, if $u_{t-1}$ is negative, dependent variable is below its equilibrium value), $\alpha_{2} u_{t-1}$ will be positive, leading dependent variable to rise in period $t$.

The post-regression diagnostic tests are conducted to detect probable bias (es) on account of the multicollinearity, autocorrelation and hetroskedastic variance in the variables understudy. The reported values of post-regression Durbin Watson, Variance Inflating Factor / Tolerance Limits (VIF \& TOL), and the Szroeter's test statistic detects autocorrelation, multicollinearity and presence of hetroscedasticity in the variables respectively. As a thumb rule it is assumed; Durbin Watson statistic value of around 2, assumes there is no first-order autocorrelation either positive or negative, the larger the VIF, or closer TOL is to one, greater the evidence that a variable is not collinear with the other regressors. The Szroeter's statistic test helps to test the null hypothesis of constant variance against alternate hypothesis of monotonic variance in variables while the Ramsey RESET omitted variable test using powers of the fitted values of regressions are used to check the null hypothesis that the model has no omitted variables. Since the Robust standard errors are reported in the regression results it should however be noted that the robust standard errors are much greater then the normal standard errors and therefore the robust $t$ ratios are much smaller than normal $t$ ratios.

In a multivariate system, the alternate cointegration procedure suggested by Johansen (1988), and Johansen and Juselius (1992) is very popularly followed in the 
recent literature. The Johansen and Juselius framework provides suitable test statistics (maximum eigen values and the trace test) to test the number of cointegrating relationship, as well as the restrictions on the estimated coefficients and involves an estimation of a vector error correction model (VECM) to obtain the likely-hood ratios (LR). The VECM runs in the following sequence

Consider a VAR of order p $y_{t}=A_{1} y_{t-1}+\ldots+A_{p} y_{t-p}+B x_{t}+\varepsilon_{t}$

Where $y_{t}$ is a k-vector of non-stationary $I(1)$ variables, $x_{t}$ is a d-vector of deterministic variables, and $\varepsilon_{t}$ is a vector of innovations.

We may rewrite this VAR as

$y_{t}=\Pi y_{t-1}+\sum_{i=1}^{p-1} \Gamma_{i} \Delta y_{t-i}+B x_{t}+\varepsilon_{t}$

where $\Pi=\sum_{i=1}^{p} A_{I}-I$, and $\Gamma_{i}=-\sum_{j=i+1}^{p} A_{j}$

Granger's representation theorem asserts that if the coefficient matrix $\rho$ has reduced rank $\mathrm{r}<\mathrm{k}$, then there exist $\mathrm{k} \times \mathrm{r}$ matrices $\alpha$ and $\beta$ each with rank $\mathrm{r}$ such that $\alpha=\alpha \beta^{\prime}$ and $\beta^{\prime} \mathrm{y}_{\mathrm{t}}$ is $\mathrm{I}(0) . \mathrm{r}$ is the number of cointegrating relations (the cointegrating rank) and each column of $\beta$ is the cointegrating vector. The elements of $\alpha$ are known as the adjustment parameters in the VEC model. Johansen's method is used to estimate the П matrix from an unrestricted VAR and to test whether we can reject the restrictions implied by the reduced rank of $\Pi$.We assume that the level data have no deterministic trends and the cointegrating equations have intercepts such as

$$
H_{1}^{*}(r): \Pi y_{t-1}+\beta x_{t}=\alpha\left(\beta^{\prime} y_{t-1}+\rho_{0}\right)
$$

In order to determine the number of $r$ cointegrating relations conditional on the assumptions made about the trend, we can proceed sequentially from $r=0$ to $r=$ k-1 until we fail to reject. The trace statistic reported in the first block tests the null hypothesis of $r$ cointegrating relations against the alternative of $\mathrm{k}$ cointegrating relations, where $\mathrm{k}$ is the number of endogenous variables, for $\mathrm{r}=0,1, \ldots . ., \mathrm{k}-1$. The alternative of $\mathrm{k}$ cointegrating relations corresponds to the case where none of the series has a unit root and a stationary VAR may be specified in terms of the levels of all of the series. The trace statistic for the null hypothesis of $r$ cointegrating relations whereas the max statistic tests the null hypothesis of $r$ cointegrating relations against 
the alternative of $r+1$ cointegrating relations. The trace statistic (tr) and the max statistics (max) are computed as

$L R_{\mathrm{tr}}(r \mid k)=-T \sum_{i=r+1}^{k} \log \left(1-\lambda_{i}\right) \quad$ and $L R_{\max }(r \mid r+1)=-T \log \left(1-\lambda_{\mathrm{r}+1}\right)$, which can be

transformed as $=L R_{\mathrm{tr}}(r \mid k)-L R_{\mathrm{tr}}(r+1 \mid k)$ for $\mathrm{r}=0,1, \ldots \ldots, \mathrm{k}-1$.

Where $\lambda_{i}$ is the $\mathrm{i}$-th largest eigenvalue of the $\Pi$ matrix in equation 16.

\section{Causality using Unrestricted VAR}

Ordinary linear regression or correlation methods cannot be used to establish a causal relation among variables. In particular it is well known that when two or more totally unrelated variables are trending over time they will appear to be correlated simply because of the shared directionality. Even after removing any trends by appropriate means, the correlations among variables could be due to causality between them or due to their relations with other variables not included in the analysis. Granger (1988) introduced a useful method to test for Granger causality between two variables. The basic idea is that if changes in $X$ precede changes in $Y$, then $X$ could be a cause of $Y$. This involves an unrestricted regression of $Y$ against past values of $Y$, with $X$ as the independent variable. The restricted regression is also required in the test, regressing $Y$ against past values of $Y$ only. This is to verify whether the addition of past values of $X$ as an independent variable can contribute significantly to the explanation of variations in $Y$, Pindyck and Rubinfeld (1998). The test involves estimating the following pair of regressions

The causal relationship between economic growth and financial development indicators is examined with the help of Granger-Causality procedure based on Unrestricted Vector Auto Regression using the error correction term. This procedure is particularly attractive over the standard VAR because it permits temporary causality to emerge from firstly, the sum of the lagged differences of the explanatory differenced variable and secondly, the coefficient of the error-correction term. In addition, the VECM allows causality to emerge even if the coefficients lagged differences of the explanatory variable are not jointly significant, Miller and Russek (1990). It must be pointed out that the standard Granger-causality test omits the additional channel of influence. VAR model is estimated to infer the number of lag terms required (with the help of simulated results using VAR) to obtain the best 
fitting model and appropriate lag lengths were then used in causality tests yielding the F-statistics and respective p-values. For any F-statistic, the null hypothesis is rejected when the p-value is significant (less than 0.05 or $5 \%$ level of significance or those stated otherwise). A rejection of the null hypothesis would imply that the first series Granger-causes the second series and vice versa. The equations 18 is now transformed to include the error correction term as depicted in the following equations respectively

$$
\Delta X_{t}=\phi_{0}+\sum_{i=1}^{p} \phi_{1, m} \Delta X_{m, t-i}+\sum_{i=1}^{q} \phi_{2} \Delta Y_{t-i}+\psi R E S_{t}+\varepsilon_{1 L}
$$

Where the error terms is taken from the following cointegrating equation $\Delta X_{t}=\beta_{0}+\beta_{m}\left(\Delta Y_{m, t}\right)+\varepsilon_{t}$

The independent variables in the equations are first differenced. The null hypothesis $\Delta \mathrm{Y}$ doesn't Granger cause $\Delta \mathrm{X}$ is rejected if the estimated coefficients $\phi_{1, m}$ as well as the estimated coefficient of error term are jointly significant.

\section{Results and Interpretations}

The decisive role of the financial system in mobilizing and allocating the resources for capital formation and economic growth has been well established by many empirical studies, Levine (1997). We attempt to point the desirability of policy measures that promote financial intermediation, in terms of the financial deepening process (FD) i.e. the extent to which or the ease at which an asset freely flows illiquid to the liquid form, the capacity of the financial system to generate savings (FS) and finally the ability trigger further financial activity (FA) through capital formation, the extent of intervention of government or monetary authority in adjusting the liquidity (LA) in the economy in order to ensure sustainable and organized economic performance (EG). The variables are expressed in its year to year growth form (where G stands for Growth) to avoid the non-stationary properties in the data.

The first two tables $(1 \& 2)$ describe the data in terms of its basic statistical descriptive and bivariate correlations. Since the time-period under consideration is longer with regards the first set of variables, table 1 divides the data period into three panels; the full period covering 1971-2004, the pre-reform period ranging 19711992, and the rest as the later. The Jarque-Bera (J-Bera) normality test rejects the 
hypothesis that the residuals are normally distributed for the full period. Since the JB test is essentially asymptotic, its values for the pre $\&$ post-reform periods are not considered. The non-parametric Kolmogorov-Smirnov $Z$ test is reported to measure the effect of reforms on the data rather then the $\mathrm{F}$ test for independent samples as the normality assumption in data is violated.

Table 1. Descriptive Statistics for Time-series Variables

\begin{tabular}{|c|c|c|c|c|c|c|c|c|c|c|c|c|c|c|c|}
\hline Variables & \multicolumn{3}{|c|}{ EG } & \multicolumn{3}{|c|}{ GFA } & \multicolumn{3}{|c|}{ GFS } & \multicolumn{3}{|c|}{ GFD } & \multicolumn{3}{|c|}{ GLA } \\
\hline Period & Full & Pre & Post & Full & Pre & ost & ull & Pre & $10 \mathrm{st}$ & Full & Pre & Post & Full & Pre & \begin{tabular}{|l|} 
Post \\
\end{tabular} \\
\hline Mean & 4.92 & 4.29 & 6.10 & 15.08 & & & .71 & .72 & 9.94 & 7 & 16.48 & & .06 & 59 & \\
\hline Iec & 31 & 4.50 & 5.99 & 7.42 & 11 & 1.58 & 71 & 11.86 & 9.74 & 12.99 & 14.57 & 10.79 & .00 & 0.00 & . \\
\hline$\overline{\operatorname{Max}}$ & 10.47 & 10.47 & 8.20 & 147.32 & 147 & 51.53 & 24.20 & 24.20 & 14.11 & 46.56 & 46.56 & 15.98 & 28.57 & 28.57 & 0.00 \\
\hline lin & .20 & -5.20 & 3.98 & \begin{tabular}{|l|}
-39.67 \\
\end{tabular} & -3 & -19.05 & 5.49 & 5.49 & 5.80 & 5.92 & 8.49 & 5.92 & -16.67 & 0.00 & -16 \\
\hline td. & 3.02 & 3.48 & 1.37 & 35.97 & 41.95 & 20.84 & 4.35 & 4.86 & 2.56 & 7.47 & 8.52 & 3.00 & 8.36 & 7.51 & 5.93 \\
\hline -Be & 13.82 & 2.45 & 0.69 & 31.12 & 8.96 & 1.81 & 7.44 & 1.91 & 0.74 & 140.03 & 344.41 & 0.30 & 19.90 & 30.6 & 0.99 \\
\hline$-\mathrm{Va}$ & $0.00^{*}$ & 0.29 & 0.71 & $0.00 *$ & $0.01 *$ & 0.40 & $02 * *$ & 0.38 & 0.69 & $0.00^{*}$ & $0.00^{\prime}$ & 0.86 & $0.00^{*}$ & $0.00^{\circ}$ & 0.61 \\
\hline KS-Z & 1.32 & $(0.06$ & )*** & 1.28 & $(0.07)$ & & 0.95 & $5(0.3$ & & 1.32 & $(0.05$ & )$^{* *}$ & 1.84 & $(0.02)$ & *** \\
\hline
\end{tabular}

Notes: 1. Full, Pre and Post denotes the full period, pre-reform and the post-reform periods respectively 2 . Figures in the parenthesis represent $P$-values 3 . KS- $Z$ statistics denote the test result of Kolmogorov-Smirnov $Z$ test for the respective variable in the post-reform period compared to the former $4 . *{ }^{*} * \& * *$ denote probabilities of 2 -tailed significance asymptotic at $1,5 \& 10$ percent levels respectively.

Since the beginning of financial liberalisation in 1992-93, India has made a remarkable turnaround with the real GDP growth marks approx. 2 percent increase compared to the previous periods. Relatively, the growth in the financial activity, financial savings, financial deepening has decreased in the later sub-periods, but the difference is not statistically significant in case of the financial savings proxy. However the turbulence in their growth is much lower in the later period compared to the former, as evident from their standard deviations. Overall, the growth in FS and FA has not been at a speed comparable with that of FD. The growth in bank rate proxied by LA is been emphasized as the potential instrument of monetary policy in India to regulate the cost and availability of refinance and to change the volume of lendable resources of banks and other financial institutions. The growth in LA has significantly strengthened in the post-reform period compared to the former, evident from the change in sign to negative in its mean values in the later periods. The bank rate was changed only 6 times during the first 27 years period until 1997 (continuously reviewed thereafter) and remained static during 1974-80, 1981-90 and 1992-96. During the 1980's, the interest rates on bank deposits and loans were changed without making any change in the bank rate. The circumspection of the RBI 
to alter liquidity through the liquidity stemmed from its desire not to adversely affect the yields and the market for government securities. One can notice the tendency of the central bank to move away from the "cost effect" to the "availability effect", and again to the "cost effect" in adjustment of liquidity in the economy as the liquidity adjustment policy tightened from $6 \%$ in 1971 to $12 \%$ during $1992-97$ periods, and reactivated at the levels of average 5.5\% in 2004 .

Table 2. Spearman's rho Correlation Matrix amongst Variables

\begin{tabular}{|l|c|c|c|c|c|}
\hline Variables & EG & GFA & GFS & GFD & GLA \\
\hline EG & 1.00 & -0.15 & $-0.69^{*}$ & $-0.69^{*}$ & -0.27 \\
\hline GFA & -0.15 & 1.00 & 0.01 & 0.14 & $0.40^{* *}$ \\
\hline GFS & $-0.69^{*}$ & 0.01 & 1.00 & $0.77^{*}$ & $0.28^{* * * *}$ \\
\hline GFD & $-0.69^{*}$ & 0.14 & $0.77^{*}$ & 1.00 & $0.29^{* * *}$ \\
\hline GLA & -0.27 & $0.40^{* *}$ & $0.28^{* * * *}$ & $0.29^{* * *}$ & 1.00 \\
\hline
\end{tabular}

Note: $1 .^{*} \& * *$ denote 2 -tailed significance at $1 \& 5$ percent levels respectively.

The non-parametric correlations are computed for the above data since the normality assumption is violated. The results reveal though the growth in economic performance is negatively related with growth in FS, FD, FA and the LA measure, the later two are not significant. These results follow earlier table reflecting the fact, other than the EG variable no other variable reports a positive development in the postreform periods compared to the former. The central monetary authority's policy to reduce its intervention in money market by gradually reducing the bank rate over the years is in tune with the government's deliberate efforts to stimulate higher economic growth. This explains the negative sign of the correlation coefficients of EG \& GLA. The low correlation between FA \& FS, and higher incase of GFS \& GFD is as per expectations as they proxy the investment and savings functions respectively. The explanation for the negative signs between EG \& FD, and growth in LA with FA calls for further analysis to confirm whether such relation is demonstrated in the short-run and the long-run. Such an assessment follows in three steps.

Firstly, we subject the time series variables to stationarity test for the existence of unit root in the time-series of above variables following ADF and PP specification, for the regression of a non-stationary time series on another nonstationary time series may produce spurious regression estimates. The unit root test presented in table 3 confirms that no variables in our models demonstrate the presence of any stochastic trends; that is they do not contain a unit root in its original form. 
Table 3. Results of the Unit Root Tests

\begin{tabular}{|l|c|c|c|c|}
\hline \multicolumn{1}{|c|}{ Model 1 At Levels } & $\begin{array}{c}\text { ADF t- } \\
\text { Statistic }\end{array}$ & Prob.* & $\begin{array}{c}\text { PP t- } \\
\text { Statistic }\end{array}$ & Prob.* \\
\hline Exogenous: Constant \& No Trend & -6.17 & $0.00^{*}$ & -5.19 & $0.00^{*}$ \\
\hline Economic Growth & -6.26 & $0.00^{*}$ & -6.35 & $0.00^{*}$ \\
\hline Growth in Financial Activity & -5.93 & $0.00^{*}$ & -5.95 & $0.00^{*}$ \\
\hline Growth in Financial Savings & -3.66 & $0.00^{*}$ & -3.70 & $0.00^{*}$ \\
\hline Growth in Financial Deepening & -3.20 & $0.01^{*}$ & -3.22 & $0.01^{*}$ \\
\hline Growth in Liquidity Adjustment & & & & \\
\hline Exogenous: Constant \& Linear Trend & -7.25 & $0.00^{*}$ & -7.50 & $0.00^{*}$ \\
\hline Economic Growth & -6.39 & $0.00^{*}$ & -6.61 & $0.00^{*}$ \\
\hline Growth in Financial Activity & -6.76 & $0.00^{*}$ & -7.19 & $0.00^{*}$ \\
\hline Growth in Financial Savings & -4.59 & $0.00^{*}$ & -4.57 & $0.00^{*}$ \\
\hline Growth in Financial Deepening & -4.73 & $0.00^{*}$ & -4.79 & $0.00^{*}$ \\
\hline Growth in Liquidity Adjustment & Fun
\end{tabular}

Notes: 1.ADF and PP are Augmented Dickey Fuller \& Philip-Perron test results respectively. 2. $\Delta$ denotes first-differences $3 . *$ denote probabilities of 2 -tailed significance asymptotic at 1 , percent levels.

Secondly, we investigate the cointegrating relationship among variables in a multivariate system to identifying the cointegrating (long-run equilibrium) relationships and gauge the extent of loadings on cointegrating relationship between the underlying variables, estimate a Johansen cointegrating to test the restrictions imposed by cointegration on the unrestricted VAR involving the series equation with a constant and without deterministic trend in the data with a unit lag. Finally we attempt to estimate the nexus between economic performance and financial infrastructure development with a VAR framework.

After confirming the data is stationary, it is possible to carry out the cointegration tests between the different proxies of financial development and the economic growth to test for the existence of a stable relationship between them. The first row in the table 4 test the hypothesis of no cointegration, the second row test the hypothesis of one cointegrating relation, and so on, all against the alternative hypothesis of full rank, i.e. all series in the VAR are stationary. To determine the number of cointegrating relations $r$, subject to the assumptions made about the trends in the series, we can proceed sequentially from $r=0$ to $r=k-1$ until we fail to reject. The first row in the upper table tests the hypothesis of no cointegration, the second row tests the hypothesis of one cointegrating relation, the third row tests the hypothesis of two cointegrating relations, and so on, all against the alternative hypothesis of full rank, i.e. all series in the VAR are stationary. The critical values for the trace statistic reported follow Osterwald-Lenum (1992). The trace statistic 
does not reject any of the hypotheses at $1 \& 5 \%$ level and Likelihood ratio test indicates 5 cointegrating equations at 5\% significance level.

Table 4. Results of the Johansen Cointegration Test

\begin{tabular}{|c|c|c|c|c|}
\hline Eigen Value & $\begin{array}{c}\text { Likelihood } \\
\text { Ratio }\end{array}$ & $\begin{array}{c}\text { 5 \% Critical } \\
\text { Value }\end{array}$ & $\begin{array}{c}\text { 1 \% Critical } \\
\text { Value }\end{array}$ & $\begin{array}{c}\text { Hypothesized } \\
\text { No. of CE(s) }\end{array}$ \\
\hline \multicolumn{5}{|c|}{ Series: EG, GFA, GFD, GFS \& GLA } \\
\hline 0.78 & 136.75 & 68.52 & 76.07 & None $^{*}$ \\
\hline 0.75 & 87.81 & 47.21 & 54.46 & At most * $^{*}$ \\
\hline 0.52 & 43.85 & 29.68 & 35.65 & At most $*^{*}$ \\
\hline 0.30 & 20.06 & 15.41 & 20.04 & At most 3 \\
\hline 0.24 & 8.70 & 3.76 & 6.65 & At most $4 *$ \\
\hline
\end{tabular}

Note: $1 . *$ denotes rejection of the hypothesis at $1 \%$ significance level

Econometrically, cointegration means that we have co-evolution of financial infrastructure development and economic indicators in India, which gives in the long run a cointegrating vector or a log run equilibrium state. The results from table 4 suggest that financial infrastructure development and economic performance indicators are integrated and there exists a long-run or equilibrium, relationship between them. Since it is possible that cointegrating variables may deviate from their relationship in the short run, but their association would return in the long run.

In order to check for the long term relationship amongst the dependent and independent variables, we subject the variables to estimation using the specifications stated in equations 10 and 11 . The reported values of post-regression statistics are displayed along with the regression coefficients in table 5 illustrating the long run relationship between the regressand with the regressors. Consequently, the short run dynamics of the variables are seen as fluctuations around this equilibrium and the ECM indicates how the system adjusts to converge to its long-run equilibrium state. The speed of adjustment, to the long run path, is indicated by the magnitudes of the coefficients of $\alpha$ vectors (i.e. $\alpha 1$ and $\alpha 2$ ). The effect of the error correction term $\beta X_{t-}$ ${ }_{l}$ on economic growth depends, first, on the sign of the adjustment coefficient $\alpha 1$ and second, on the sign of $\beta X_{t-1}$ itself since $\beta X_{t-1}$ is a stationary process and may be positive, negative or equal to zero. The values of $r$ square and the significance of the $F$-statistic model denote that the fitted model explains the data well in the long-run as well as the short-run. The post-regression diagnostic tests rule out any serious problems in the series, further robust standard errors are used in the regression corrects for bias if any. The estimated coefficients in the models don't deviate much in the short \& the long-run. The error correction term however model (ECM) in spirit 
of Sargan (1984), \& Granger (1988) reveals whether the dependent variables adjusts to the explanatory variables in the same period as well as the magnitude of the speed of such adjustment.

Table 5. VECM Estimates for the Economic Growth Model

\begin{tabular}{|c|c|c|c|c|c|}
\hline \multicolumn{6}{|c|}{ Coefficients with P- values for Long-Run Cointegration } \\
\hline $\begin{array}{l}\text { Dependent } \\
\text { Variable }\end{array}$ & $\begin{array}{l}\text { Independent } \\
\text { Variables }\end{array}$ & Coefficients & $\begin{array}{l}\text { Robust } \\
\text { Std. Er }\end{array}$ & $t$-Stat & Prob. \\
\hline \multirow{5}{*}{ EG } & Constant & 11.93 & 0.94 & 12.69 & $0.00^{*}$ \\
\hline & GFA & -0.02 & 0.01 & -2.45 & $0.02 * *$ \\
\hline & GFS & -0.61 & 0.10 & -5.88 & $0.00 *$ \\
\hline & GFD & 0.03 & 0.06 & 0.47 & 0.64 \\
\hline & GLA & 0.00 & 0.02 & 0.02 & 0.99 \\
\hline \multicolumn{6}{|c|}{$\begin{array}{l}\text { R-squared= 0.68 Durbin-Watson }=1.84 F \text {-statistic }=17.19(0.00)^{*} \\
\text { Mean VIF, TOL }=1.32,0.77 \text { ADF test for Residual }=-5.46(0.00)^{*}\end{array}$} \\
\hline \multicolumn{6}{|c|}{ Coefficients with P- values for Short-Run Cointegration } \\
\hline \multirow{6}{*}{$\Delta \mathbf{E G}$} & Constant & 0.08 & 0.31 & 0.26 & 0.79 \\
\hline & $\Delta$ GFA & -0.01 & 0.01 & -1.95 & $0.06^{* * * *}$ \\
\hline & $\Delta$ GFS & -0.57 & 0.06 & -10.31 & $0.00 *$ \\
\hline & $\Delta$ GFD & -0.02 & 0.04 & -0.50 & 0.62 \\
\hline & $\Delta$ GLA & 0.03 & 0.04 & 0.86 & 0.40 \\
\hline & $u_{t-1}$ & -0.99 & 0.19 & -5.17 & $0.00 *$ \\
\hline
\end{tabular}

Note: a. $\mathrm{G}$ denotes Growth and $\Delta$, the first difference operator $\mathbf{b} .{ }^{*}, * * \& * * *$ denote probabilities of 2-tailed significance asymptotic at $1,5 \& 10$ percent levels respectively.

As per expectations and in tandem with the results of the correlation matrix, the dependent variable economic growth bears a significantly inverse relation with the financial activity generating from the private corporate sector and financial savings, an economy is able to generate. The corporate sector in India is a deficit one that borrows funds from other sectors, mainly households, either directly or intermediated through banks or non-bank financial institutions. It then invests over and above internal funds, either in capital formation that takes the form of investments in physical assets, such as land, building, machinery or stocks, or in financial assets such as loans and advances, securities and sundry credit. Plunging gross capital formation by the private sector could be due to non-availability of funds from other sectors, as these sectors themselves have lucrative investment avenues. The impact of financial savings on economic growth is significantly negative and the largest. Since higher growth entails higher growth in economic activity, more investment opportunities and returns, slack in financial savings is eminent. The 
magnitude of both these variables is constant both, in the short-run as well as in the long-run. The variable GFD, representing liquid liabilities to GDP has a positive impact on the growth proxy in the long-run while negative in the short-run, though the magnitude is small and insignificant. The positive collaboration of the growth in liquidity adjustment to the extent of 0.03 points with growth in economic activity is tenable only in the short-run and has no effect in the long run. The error correction term describes the speed of adjustment back to equilibrium, and its strict definition is that it measures the proportion of last period's equilibrium error that is corrected for. The error correction term is highly significant and has the expected negative sign. Since $u_{t-1}$ (i.e.) economic growth is below its equilibrium value), The sign indicates, that if the difference between the dependent variables and the respective regressors in the model are positive in one year, the growth rates of the dependent variable will fall during the next period to restore equilibrium, and vice versa.

To check the robustness of these results, we check the dynamic interaction between the cointegrated variables in the long run and how each one is causing the other. According to Granger (1988), if two variables are cointegrated, then we wait for Granger causation in at least one direction. The hypothesis test for the dynamic interaction between the cointegrated variables through Unrestricted VAR are presented in table 7 (in Appendix ) based on the lag order selection criteria in table 6.

Table 6. Lag Length Selection Criteria

\begin{tabular}{|c|c|c|c|c|c|c|}
\hline Lag Level & LL & LR & FPE & AIC & HQIC & SBIC \\
\hline 0.00 & -660.39 &. & $1.27 \mathrm{E}+13$ & 44.36 & 44.43 & 44.66 \\
\hline 1.00 & -607.64 & 105.50 & $2.05 \mathrm{E}+12$ & 42.51 & 42.96 & 43.91 \\
\hline 2.00 & -561.37 & $92.543^{*}$ & $5.77 \mathrm{e}+11^{*}$ & $41.091^{*}$ & $41.9128^{*}$ & $43.59^{*}$ \\
\hline
\end{tabular}

Notes: 1. Results of the Likelihood Ratio (LR), the Final Prediction Error (FPE), the Akaike Information criteria (AIC), the Hannan and Quinn Criteria (HQ), and the Schwarz Bayesian Criteria (SBC) 2.* indicate optimum lag length for the respective criterion column

The results for economic performance and infrastructure development causality are distinct. First, in the short run we find significant support for the hypothesis that growth in financial infrastructure causes growth in economic performance but no support for the contrary. In the long run, independence or no causality is suggested between the two. That is, there is no evidence that economic growth and growth in financial infrastructure cause and affect each other in the longrun and this may be because the financial sectors in India observed long periods of total public control and full government intervention in the determination and the 
allocation of financial resources to capital accumulation. Second, the country is reforming gradually its financial sector in terms of improving their institutional and regulatory infrastructure. The transformation process of the intermediaries is far more from complete. As a consequence, the expected positive effects of these financial liberalization policies on long-run economic growth can not be seen before the achievement of full and total liberalization of financial structures and especially the liberalization of capital accounts. Significantly, there exists unidirectional causality between growth in financial deepening and a spurt in economic activity and a unidirectional causality is noticed from growth in economic activity towards growth in financial activity. Bidirectional causality is suggested between growths in financial activity with the growth in financial savings and causes financial deepening. Increase in Liquidity adjustment measures by the central banker results in more financial savings in order to benefit from higher returns due to higher interest rates.

\section{Summary and Policy Implications}

The coherent picture which emerges from Johansen cointegration and the ECM tests is that there is evidence in favor of a short run effect of "financial infrastructure led economic growth". Finance is found to be a leading sector, only, in the short-term link in Granger causality tests with stationary variables. Moreover, Granger-causality test based on vector error correction model (VECM) further reveals that in the long run, stock market development Granger-causes infrastructural growth. Hence, this study provides robust empirical evidence in favor of finance-led growth hypothesis for the Indian economy.

The financial infrastructure development indicators for the overall economy have a highly positive causation coefficient with the economic activity implying that they have developed together. Our findings suggest that the evolution of financial sector tends to, or is more likely to stimulate and promote economic growth when monetary authorities adopt liberalized investment and openness policies, improve the size of the market intone with the macroeconomic stability. Development of financial infrastructure can do a good job of delivering essential services and can make a huge difference to a country's economic growth. Ensuring robust financial sector development with the minimum of crises is essential for growth and reducing transaction cost and inefficiencies as has been repeatedly shown by recent research findings. 
Government ownership of infrastructure and interference of monetary authorities continues to be remarkably widespread in India, despite clear evidence that the goals of such ownership and interference are rarely achieved, and that it weakens the financial system rather than the contrary. However, the issues of complete autonomy to the supervisory and regulatory agencies, full convertibility on capital account and privatization of banking systems has to be designed carefully if the benefits are to be gained and the risks of an early collapse minimized. Facilitating convertibility and the entry of reputable foreign financial firms to the local financial market should be welcomed as they bring competition, improve efficiency, and lift the quality of the financial infrastructure. As such, they are an important catalyst for the sort of financial development that promotes growth. Capital inflows can also help Indian financial system to securely integrate itself with the world financial system through ownership and portfolio links enabling diversification of risks. Thirdly, regulation and supervision of small domestic systems is disproportionately costly, and even a well-funded effort would be hard pressed to ensure stability if finance is restricted to domestic institutions operating locally. Domestic financial systems fall short of minimum efficient scale and thus have much to gain from outsourcing financial services from abroad. Public effort must be oriented not only toward the promotion of real growth, but also continuing financial liberalization processes. There is a need to support, nurture and decentralize institutional and fiscal infrastructure, relax entry norms relating foreign investments, and amend archaic regulations. Our results point such lacunae inhibits the flowering of the Indian economy's ability to its fullest potential.

\section{References}

Agarwal, R. N. 1996. Financial Liberalisation in India: Banking system and Stock Markets. Delhi: D.K. Publishers.

Agarwal, R. N. 1997. "Inflow of Foreign Portfolio Investment in Developing Countries: A study of Determinants and Macroeconomic Impact". The Indian Economic Review, Vol.32, No.2, PP. 217-229.

Arestis, P. and Demetriades, P. 1997. "Financial Development and Economic Growth: Assessing the Evidence". The Economic Journal, 107(May): 783-799. 
Bencivenga, Valerie et Smith, Bruce, 1991. "Financial Intermediation and Endogenous Growth". Review of Economic Studies, 58:195-209.

Bhole, L. M. 1999. Financial Institutions and Markets: Structure, Growth and Innovations. $3^{\text {rd }}$ Edition. New Delhi: Tata McGraw-Hill Publishing Company Limited.

Cameron, R. 1967. Banking in Early Stages of Industrialization. New York: Oxford University Press.

Chandavarkar, A. 1992. "Of Finance and Development: Neglected and Unsettled Questions". World Development, 20(Jan.): 133-142.

Demetriades, P. and Hussein, K. A. 1996. "Does Financial Development Cause Economic Growth? Time-series Evidence from 16 Countries". Journal of Development Economics, 51: 387-411.

Demetriades, P. and Luintel, K. 1996. "Financial Development, Economic Growth and Banking Sector Controls: Evidence from India". The Economic Journal, 106: 359-374.

Demirguc-Kunt A. and Levine, R. 1996. "Stock Markets, Corporate Finance and Economic Growth: An Overview”. World Bank Economic Review, 10.

Engle, R. and Granger, C. W. J. 1987. "Cointegration and Error-correction: Representation, Estimation and Testing”. Econometrica (55): 251-276.

Fry, M. J. 1997. "In Defense of Financial Liberalization”. The Economic Journal, 107(May): 754-770.

Goldsmith, R. 1969. "Financial structure and Development". New Haven, CT: Yale University Press.

Granger, C. W. J. 1969. "Investigating Causal Relations by Econometric Methods and Cross-Spectral Methods". Econometrica, 37, 424-438.

Granger, C. W. J. 1980. "Testing for Causality: A Personal Viewpoint”. Journal of Economic Dynamics and Control, 2,329-352.

Granger, C. W. J. 1981. "Some Properties of Time Series Data and their Use in Econometric Model Specification”. Journal of Econometrics, 16, 121-130.

Granger, C. W. J. 1988. “Granger Causality, Cointegration, and Control”. Journal of Economic Dynamics and Control, 12: 551-59.

Greenwood, J. and Smith, B. 1997. "Financial Markets in Development, and the Development of Financial Markets”. Journal of Economic Dynamic and Control, 21: 145-181.

Gujarati, D. 1995. Basic Econometrics. New York: McGraw -Hill.

Gupta, K.L. (1984), “Finance and Economic Growth in Developing Countries”. London: Croom Helm 
Gurley, J. G. and Shaw, E. S. 1955. "Financial Aspects of Economic Development". American Economic Review, 45(Sept): 515-538.

Johansen, S. 1988. "Statistical Analysis of Co-integrating Vectors". Journal of Economic Dynamic and Control, 12: 231-254.

Johansen, S. and Juselius, K. 1990. "Maximum Likelihood Estimation and Inference on Cointegration with Application to the Demand for Money". Oxford Bulletin of Economics and Statistics, 52: 169-210.

Johansen, S. and Juselius, K. 1992. Some Structural Hypotheses in a Multivariate Cointegration Analysis of Purchasing Power Parity and the Uncovered Interest Parity for UK. Denmark: University of Copenhagen.

Jung, W. S. 1986. "Financial Development and Economic Growth". Economic Development and Cultural Change, 34: 336-346.

Khan, M. S. and Senhadji, A.S. 2000. "Threshold Effects in the Relationship Between Inflation and Growth". IMF Working Paper 00/110. Washington: International Monetary Fund.

King, R. and Levine, R. 1993. "Financial Intermediation and Economic Development" in Financial Intermediation in the Construction of Europe, ed. by Colin Mayer and Xavier Vives, PP. 156-89.

King, R. and Levine, R. 1993b. "Finance, Entrepreneurship and Growth: Theory and Growth”. Journal of Monetary Economics, 32(Dec): 513-542.

Kul B. L. and Khan, M. 1999. "A Quantitative Reassessment of the Finance growth Nexus: Evidence from a Multivariate VAR". Journal of Development Economics

Levine, R. 1997. "Financial Development and Economic Growth: Views and Agenda". Journal of Economic Literature, 25(June): 688-726.

Lucas, R. E. Jr. 1988. “On the Mechanics of Economic Development”. Journal of Monetary Economics, 22(July): 3-42.

Luintel, K.B. and Khan, M. 1999. "A Quantitative Reassessment of the Finance-Growth Nexus: Evidence from a Multivariate VAR". Journal of Development Economics, 60, $381-405$.

McKinnon, R. 1973. Money and Capital in Economic Development. Washington: Brookings Institution.

MacKinnon, J. G. 1991. "Critical Values for Cointegration Tests." In Long Run Equilibrium Relationships: Readings in Cointegration, edited by R. F. Engel and C. W. Granger. Oxford: Oxford University Press. 
Murinde, V. et F. Eng 1994, "Financial Development and Economic Growth in Singapore: Demand-following of Supply-leading ?" , Applied Financial Economics, 4, 391-404

Newlyn, W.T. 1977. "The Financing of Economic Development" , Clarendon press, Oxford.

Niles, H. 1994. "Financial Development \& Economic Growth: A Survey of the Literature". International Journal of Development Banking, January.

Osterwald-Lenum, M., 1992. "A Note with Quintiles of Asymptotic Distribution of the ML Co-integration Rank Statistic". Oxford Bulletin of Economics and Statistics, 54: 461472 .

Pagano, M. 1993. "Financial Markets and Growth: An Overview". European Economic Review, 37(Apr): 613-622.

Patrick, H. 1966. "Financial Development and Economic Growth in Underdeveloped Countries". Economic Development and Cultural Change, 14: 174-189.

Phillips, P.C.B. \& Perron, P. 1988. "Testing for a Unit Root in Time Series Regression," Biometrika, 75, 335-346.

Pindyck. R. S., and Rubinfeld, D. L. 1998. "Econometric Models and Economic Forecasts, " 4th Ed. New York: McGraw-Hill.

Robinson, J. 1952. "The Rate of Interest and Other Essays". London: Macmillan.

Romer, P. M. 1990. "Endogenous Technological Change". Journal of Political Economy, 98, S71-S102.

Schumpeter, J. A. 1912. "Theorie der Wirtschaftlichen Entwicklung” (The Theory of Economic Development ). Leipzig: Dunker\& Humblot, Translated by Redvers Opie, Cambridge, MA: Harvard University Press, 1934.

Shaw, E. 1973. Financial Deepening in Economic Development. New York: Oxford University Press.

Sims, C. A. 1972. "Money Income and Causality" American Economic Review, (62): $540-552$.

World Bank 1989. World Development Report (1989), New York: Oxford University Press for the World Bank.

World Bank 1996. Global Economic Prospects and the Developing Countries.

Toda, H. and P.C.B. Phillips 1993. "Vector Auto-regressions and Causality" Econometrica, 61:1367-1393. 


\section{Appendix}

Table 7. Granger Causality Wald Test with 2 Lags

\begin{tabular}{|c|c|c|}
\hline Null Hypothesis & $\begin{array}{l}\text { Coefficients with P- } \\
\text { values for Short-Run } \\
\text { Non-Causality }\end{array}$ & $\begin{array}{c}\text { Coefficients } \\
\text { with P-values } \\
\text { for Long-Run } \\
\text { Non-Causality }\end{array}$ \\
\hline \multicolumn{3}{|l|}{ Effect $=$ Economic Growth } \\
\hline Growth in FA does not Granger Cause EG & $2.61(0.27)$ Fail to Reject & \multirow{5}{*}{$\begin{array}{c}1.86(0.40) \\
\text { Fail to Reject }\end{array}$} \\
\hline Growth in FS does not Granger Cause EG & $3.10(0.21)$ Fail to Reject & \\
\hline Growth in FD does not Granger Cause EG & $15.05(0.00)^{*}$ Reject & \\
\hline Growth in LA does not Granger Cause EG & $2.64(0.27)$ Fail to Reject & \\
\hline Financial Infrastructure does not Granger Cause EG & $23.21(0.01)^{* *}$ Reject & \\
\hline \multicolumn{2}{|l|}{ EG does not Granger Cause Financial Infrastructure } & $\begin{array}{c}0.58(0.74) \\
\text { Fail to Reject } \\
\end{array}$ \\
\hline \multicolumn{3}{|l|}{ Effect $=$ Financial Activity } \\
\hline EG does not Granger Cause Growth in FA & $5.46(0.07)^{* * *}$ Reject & \multirow{5}{*}{$\begin{array}{c}0.55(0.76) \\
\text { Fail to Reject }\end{array}$} \\
\hline GFS does not Granger Cause Growth in FA & $5.29(0.07)^{* * *}$ Reject & \\
\hline GFD does not Granger Cause Growth in FA & $4.82(0.09)^{* * *}$ Reject & \\
\hline GLA does not Granger Cause Growth in FA & $4.04(0.13)$ Fail to Reject & \\
\hline All 4 Variables (Jointly) does not Granger Cause GFA & $42.31(0.00) *$ Reject & \\
\hline \multicolumn{3}{|l|}{ Effect $=$ Financial Savings } \\
\hline EG does not Granger Cause Growth in FS & $3.50(0.17)$ Fail to Reject & \multirow{5}{*}{$\begin{array}{c}3.09(0.21) \\
\text { Fail to Reject }\end{array}$} \\
\hline GFA does not Granger Cause Growth in FS & $3.81(0.15)^{* * * *}$ Reject & \\
\hline GFD does not Granger Cause Growth in FS & $12.21(0.00) *$ Reject & \\
\hline GLA does not Granger Cause Growth in FS & $10.78(0.00)^{*}$ Reject & \\
\hline All 4 Variables (Jointly) does not Granger Cause GFS & $36.43(0.00) *$ Reject & \\
\hline \multicolumn{3}{|l|}{ Effect $=$ Financial Deepening } \\
\hline EG does not Granger Cause Growth in FD & $0.81(0.67)$ Fail to Reject & \multirow{5}{*}{$\begin{array}{c}2.95(0.23) \\
\text { Fail to Reject }\end{array}$} \\
\hline GFA does not Granger Cause Growth in FD & $5.15(0.08)^{* * *}$ Reject & \\
\hline GFS does not Granger Cause Growth in FD & $0.79(0.68)$ Fail to Reject & \\
\hline GLA does not Granger Cause Growth in FD & $0.90(0.64)$ Fail to Reject & \\
\hline All 4 Variables (Jointly) does not Granger Cause GFD & $30.64(0.00) *$ Reject & \\
\hline \multicolumn{3}{|c|}{ Effect $=$ Liquidity Adjustment } \\
\hline EG does not Granger Cause Growth in LA & $0.23(0.89)$ Fail to Reject & \multirow{5}{*}{$\begin{array}{c}0.39(0.82) \\
\text { Fail to Reject }\end{array}$} \\
\hline GFA does not Granger Cause Growth in LA & $0.54(0.76)$ Fail to Reject & \\
\hline GFS does not Granger Cause Growth in LA & $1.60(0.45)$ Fail to Reject & \\
\hline GFD does not Granger Cause Growth in LA & $1.47(0.48)$ Fail to Reject & \\
\hline All 4 Variables (Jointly) does not Granger Cause GLA & $8.95(0.54)$ Fail to Rej & \\
\hline
\end{tabular}

Note: Same as in Table 5. 